\title{
CONCEPÇÕES FREIRIANAS PARA A EDUCAÇÃO NA CONTEMPORANEIDADE: DESAFIOS EMERGENTES
}

FREIRE'S CONCEPTIONS ON EDUCATION IN CONTEMPORARY TIMES: EMERGING CHALLENGES

CONCEPCIONES FREIREANAS SOBRE LA EDUCACIÓN EN LA CONTEMPORANEIDAD: DESAFÍOS EMERGENTES

\author{
TESSARO, Mônica ${ }^{1}$ \\ PAULO, Fernanda dos Santos² \\ TREVISOL, Maria Teresa Ceron ${ }^{3}$
}

\begin{abstract}
RESUMO
O artigo analisa as contribuições da pedagogia freiriana para compreensão de desafios atuais da área da educação, tais como: educação emancipatória; formação humana; formação docente e organização curricular na escola. Trata-se de uma revisão bibliográfica a partir de algumas obras de Paulo Freire. Assim, a partir da análise realizada, apresenta-nos alguns princípios de resistência ante os desafios educacionais contemporâneos: i) o diálogo como via de uma educação emancipadora e humanizadora; e ii) a própria educação escolar objetivando a conscientização de homens e mulheres, por meio de práticas pedagógicas embasadas na cooperação e a comunhão entre os sujeitos.
\end{abstract}

Palavras-chave: Paulo Freire. Educação. Desafios contemporâneos.

\section{ABSTRACT}

The article aimed to analyse the contributions of Paulo Freire's pedagogy to the comprehension of current challenges in the educational field, such as: emancipatory education, formation, teaching training and curricular organization in schools. This is a bibliographic review based on some of the works by Freire. Freire presents us some principles of resistance in front of the contemporary educational challenges: i) dialogue as a way of emancipatory and humanizing education; and ii) school education that aims to raise awareness of men and women, through pedagogical practice based on cooperation and community among subjects.

Keywords: Paulo Freire. Education. Current challenges.

\section{RESUMEN}

El artículo analiza las contribuciones de la pedagogía freiriana para la comprensión de desafíos actuales del área de educación, tales como: educación emancipadora; formación humana; formación docente y organización curricular en la escuela. Se trata de una revisión bibliográfica a partir de algunas obras de Paulo Freire. Así, a partir del análisis realizado, no presenta algunos principios de resistencia ante los desafíos educacionales contemporáneos: i) el dialogo como vía de una educación emancipadora y humanizadora; y ii) la propia educación escolar objetivando la concientización de hombres y mujeres, por medio de prácticas pedagógicas pasmadas en la cooperación y la comunión entre los sujetos.

Palabras clave: Paulo Freire. Educación. Desafíos actuales.

\footnotetext{
${ }^{1}$ Universidade do Oeste de Santa Catarina - Unoesc - Joaçaba - Santa Catarina - Brasil.

2 Universidade do Oeste de Santa Catarina - Unoesc - Joaçaba - Santa Catarina - Brasil.

${ }^{3}$ Universidade do Oeste de Santa Catarina - Unoesc - Joaçaba - Santa Catarina - Brasil.
} 


\title{
INTRODUÇÃO
}

O século XX foi marcado, entre outras conquistas, pelo triunfo da escolarização, cujo desenvolvimento foi acompanhado por uma coleção de promessas que tiveram origem no século das luzes e que segundo Canário (2006, p. 12), "associam escola, razão e progresso." Porém, a realidade não concretizou as promessas, o que manifestou na educação escolar, a passagem da euforia ao desencanto. De acordo com Canário (2006), quanto mais a sociedade foi se escolarizando mais se deparou e continua se deparando, com problemas de ordens sociais, econômicas, políticas, culturais e ambientais, que segundo o autor, se configuram em autênticos impasses da humanidade. Significa dizer, que de um lado existe um descompasso entre o conhecimento científico e técnico, característico da evolução da sociedade e, de outro, a imaturidade social e política, evidenciada pela incapacidade de administrar os efeitos colaterais do progresso.

Com o progresso reduzido aos mecanismos econômicos, e os valores reduzidos às vantagens individuais, a humanidade encontra-se acuada diante de um contexto estrutual desumanizante, nas palavras de Dowbor (1995, p. 8),

\begin{abstract}
o ser humano maneja potentes agrotóxicos, armas nucleares e bacteriológicas [...] tecnologias incomparavelmente mais avançadas do que a sua maturidade política. Isto pode ser constatado através da destruição da vida nos rios e nos mares, da erosão da camada de ozônio, do aquecimento global, das chuvas ácidas, da erosão dos solos, da expansão do consumo de drogas [...]. A humanidade não poderá sobreviver sem formas mais avançadas de organização social, capazes de ultrapassar esse caos articulado de interesses corporativos que nos acostumamos a chamar de neoliberalismo.
\end{abstract}

Diante desse cenário, compreendemos que a importância da educação e da responsabilidade dos(as) professores(as) aumenta. Espera-se da educação escolar respostas para que possamos encontrar alternativas que nos possibilitem identificar saídas para esses dilemas. Isso implica em concepções teórico-práticas "que valorizem uma função crítica e emancipatória que permita compreender o passado, problematizar o futuro e intervir de modo transformador e lúcido no presente." (CANÁRIO, 2006, p. 8). O que nos remete a uma superação da concepção bancária da educação, que para Freire (2000, p. 49) não é lutar contra essa realidade, a qual seria uma luta sem sentido, "mas como estimular o desenvolvimento da curiosidade e do pensar crítico."

Desta forma, o futuro da educação escolar deve ser encarado mais como desafiador e problemático e menos, como uma fatalidade imposta, pois para Freire (2000, p. 44), "se é possível nos defender do frio ou do calor, se é possível desviar leitos de rios, fazer barragens, se é possível mudar o mundo que não fizemos, o da natureza, por que não mudar o mundo que fazemos, o da cultura, o da história, o da política?"

Passado duas décadas dessas reflexões, o cenário desafiante da educação escolar permanece. Encontramo-nos na entrada do século XXI e na virada de mais uma década (2020) razão oportuna para continuar as análises sobre os desafios e perspectivas da educação. Para Gadotti (2000, p. 4) "falar de perspectivas atuais da educação é também falar, discutir, identificar o espírito presente no campo das ideias, dos valores e das práticas educacionais que as perpassa, marcando o passado, 
caracterizando o presente e abrindo possibilidades para o futuro." O que se sabe, é que muitos dos embates do contexto do século XX, ainda hoje, estão presentes no meio educacional. Vivemos um tempo de expectativas e perplexidades, é um momento marcado por novos e velhos desafios, os quais podem ser transformados em possibilidades.

De acordo com Demo e Silva (2020), a escola enfrenta diferentes problemas criados por modismos das políticas educacionais. Atualmente, o que mais tem se destacado são problemas ideológicos, resultado de uma política que busca expurgar Paulo Freire da educação por meio de uma militarização da escola, acreditando que o disciplinamento está no centro da formação humana. Para os autores, a finalidade precípua da escola não é a doutrinação, "mas formação intelectual e ética do estudante, o que implicadisciplina, mas não faz dela sua razão maior de ser." (DEMO, SILVA, 2020, p. 422).

Neste sentido, organizamos esse texto tendo como objetivo: Analisar as contribuições da pedagogia freiriana para compreensão de desafios atuais da área da educação, tais como: educação emancipatória, formação humana, formação docente e organização curricular na escola.

O caminho metodológico utilizado é resultado de uma revisão bibliográfica efetuada em obras freirianas que continuam sendo atuais e possuem potencial para analisar e discutir o contexto educacional atual, pois, Freire (1997, p.12) nos apresenta "uma pedagogia fundada na ética, no respeito à dignidade e à própria autonomia do educando." Realizou-se uma análise de conteúdo, buscando "desvendar o conteúdo latente" (TRIVIÑOS, 1987, p. 162) que suas obras possuem, em relação ao "novo" arranjo pelo qual os currículos escolares estão moldados. Diante disso, pretendemos explorar o legado freiriano e suas contribuições para a educação escolar na contemporaneidade. Quando nos referimos aos quatro desafios educacionais, compreendemos a existência de uma diversidade deles, Gadotti (2000), por exemplo cita: cidadania; planetaridade; sustentabilidade; virtualidade; globalização; transdisciplinaridade; dialogicidade-dialeticidade. Entretanto, no presente texto, os desafios escolhidos serão tratados como elementos centrais das discussões, os quais são compreendidos da seguinte forma:

i) Educação emancipatória: A pedagogia de Paulo Freire tem nos revelado que a educação emancipatória implica vivências e participação crítica, diálogo comprometido, construções coletivas, conhecimento transformador e ruptura de qualquer tipo de opressão.

ii) Formação humana: Compreendemos a formação humana enquanto totalidade, cujas dimensões epistemológicas, pedagógicas, metodológicas, políticas e sociais estão integradas. O ponto de partida desse desafio é problematizarmos os sentidos e significados do conhecimento oportunizados pela escola.

iii) Formação docente: Embora compreendemos a formação humana enquanto totalidade, não perdemos de vista que a formação de professores(as) é uma dimensão da educação escolar que deve ser levada a sério, pois é listada entre as prioridades da 
pedagogia freiriana, compreendida como caminho para tornar a educação escolar mais humana. Para Freire (1993a) a formação docente deve ser permanente, devido a consciência ontológica dos sujeitos, ou seja, "educação é permanente na razão, de um lado, da finitude do ser humano, de outro, da consciência que ele tem de sua finitude." (FREIRE, 1993a, p. 22-23). E ainda, "na formação permanente dos professores, o momento fundamental é o da reflexão crítica sobre a prática. É pensando criticamente a prática de hoje ou de ontem que se pode melhorar a próxima prática." (FREIRE, 1996, p. 39).

iv) Organização curricular na escola: Em tempos de reformas curriculares, embasadas por pressupostos que enfatizam a natureza operacional dos conhecimentos, faz-se necessário ressignificar as contribuições de Paulo Freire, visando a reestruturação curricular a partir do diálogo entre os diferentes saberes, considerando a interdisciplinaridade como constituinte de uma educação crítica e problematizadora com vistas a transformação da sociedade. Pois uma escola com "apenas aula, prova e repasses [...] não vamos além do treinamento domesticador." (DEMO, SILVA 2020, p. 422).

Tais desafios são complexos e refletem fatores que extrapolam a dimensão da educação escolar, estando enraizados na atual conjuntura político-econômica. Por isso, potencializar espaços formativos para o enfrentamento desses desafios pode representar um caminho promissor para contribuir com uma educação escolar mais humanizadora e emancipadora (IVENICKI, 2019). Por essa razão, consideramos que esses desafios devem estar articulados e presentes nas propostas educacionais do século XXI, em contraposição aos pocotes prontos de educação, que pouco contribuem para a emancipação do humano.

\section{PAULO FREIRE E OS DESAFIOS CONTEMPORÂNEOS DA EDUCAÇÃO ESCOLAR}

Partindo dos desafios propostos para este artigo, neste item, iremos analisar cada um deles na perspectiva freiriana buscando realizar aproximações com a educação escolar do século XX, mas principalmente, analisá-los a luz das perspectivas atuais. Nesse sentido, corroboramos com Teixeira (1963) que não podemos refletir sobre o atual estado da educação escolar sem algumas ponderações, breves que sejam, sobre o seu desenvolvimento, especialmente porque a escola reflete a estrutura do contexto em que está inserida.

Nessa continuidade, compreendemos que a escola do século XXI não é a mesma e nem está situada na mesma sociedade que marcou o século XX. A instituição escolar sofreu transformações que Canário (2006, p. 16) sintetiza na seguinte afirmação "a escola passou de um contexto de certezas, para um contexto de promessas, inserindo-se, atualmente, em um contexto de incertezas." A escola das certezas representada pela escola do século XX, foi constituída por valores estáveis, funcionando 
como um registro eletista. Essa era uma instituição voltada a formar lideranças, ou seja, só os melhores (intelectualmente e economicamente falando) tinham acesso ao ensino médio e ao ensino superior, por essa razão, alguns alcançavam a ascenção social e outros eram excluídos do processo de escolarização (CANÁRIO, 2006).

Com a chegada da industrialização, advento que muda a estrutura da sociedade, houve a necessidade de ampliação da mão de obra para o mercado. Portanto, nasce a escola das promessas que segundo Canário (2006), foi um período caracterizado pela expansão das unidades escolares, associado a três promessas: desenvolvimento, mobilidade social e igualdade. As pessoas precisavam aprender a ler e a escrever para dar conta da demanda industrial que estava surgindo. Entretanto, segundo Teixeira (1963) foi uma época marcada pela reprodução das desigualdades sociais, ocasionando frustrações e desencantos, marcando a entrada da educação na era das incertezas. Nesse novo contexto a escola passa a alimentar os processos de exclusão, representando um jogo de soma nulo, onde o sucesso de uns corresponde ao fracasso de outros (CANÁRIO, 2006).

Portanto, a forma como o futuro da educação escolar poderá vir a ser esculpido dependerá das respostas aos dilemas impostos pelos sistemas educacionais, nessa linha, vislumbremos dois posicionamentos: no primeiro, poderá continuar seguindo os critérios da subordinação calcados na realidade econômica, que atualmente se constitui a base dos problemas sociais, ou ao contrarário, a segunda alternativa é apostar em uma educação escolar alicerçada nas virtudes emancipatórias, de transformações sociais e na ação educativa crítica e reflexiva (CANÁRIO, 2006). Nessa útilma perspectiva, destaca-se a necessidade de organização do trabalho coletivo, que por intermédio do diálogo e da democracia, poderá criar espaços contra-hegemônicos (IVENICKI, 2019).

Em linha com essas argumentações, concordamos com Freire (1991) que (re)formular a escola é um ato político que precisa ser encarado com consciência ética, pois sabemos que,

mudar a cara da escola pública implica também ouvir meninos e meninas, sociedades de bairro, pais, mães. Diretoras, delegados de ensino, professoras, supervisoras, comunidade científica, zeladores, merendeiras [...]. Implica a participação política das classes populares através de suas representações ao nível das opções, das decisões e não só do fazer o já programado. (FREIRE, 1991, p. 35 - 75)

Não podemos idealizar e perspectivar transformações na educação escolar sem considerar às condições reais das escolas. Visto que para Freire (1991), as escolas não são apenas espírito, mas são corpo também e, a prática educativa cuja política e estruturação curricular nos cabe traçar, de forma democrática, se dá na dimensão concreta da escola, situada em um espaço/tempo, não apenas na cabeça das pessoas.

Diante dessas contribuições, a escola sonhada por Freire (1991, p.37) é uma instituição que "se dedique ao ensino de forma competente, mas, [...] seja uma escola geradora de alegria [...]. Precisamos é remover os obstáculos que dificultam que a alegria tome conta de nós e não aceitar que ensinar e aprender são práticas necessariamente enfadonhas e tristes." Nesse sentido, a educação escolar deve, necessariamente, desejar evoluir, especialmente no que diz respeito ao trabalho colaborativo envolvendo toda comunidade escolar, esse processo de 
reinvenção/reestruturação/transformação, para Canário (2006, p.19) "apela para uma ação estrategicamente orientada para a incidência em pontos críticos."

Nessa linha, apresentamos as preocupações de Gadotti (2000) relacionadas à educação neste novo milênio, para ele, a educação está diante de uma dupla encruzilhada: de um lado, o sistema escolar não deu conta de universalizar a qualidade da educação básica, de outro, mesmo com as mudanças, as novas matrizes teóricas que orientam o currículo escolar, não apresentam consistência necessária para indicar caminhos mais democráticos e éticos nesta época de profundas transformações. Portanto, para Gadotti, um dos desafios da educação escolar na contemporaneidade está em buscar, por meio do legado freiriano, respostas à essa crise de paradigmas.

As concepções teórico práticas desenvolvidas por Paulo Freire a partir do conceito de Escola Cidadã, poderão constituir-se em estratégias de enfrentamento ao projeto neoliberal de educação (GADOTTI, 2000). Portanto, falar dos desafios da educação escolar no contexto/tempo contemporâneo, significa falar de "uma educação contestadora, superadora dos limites impostos pelo Estado e pelo mercado, portanto, uma educação muito mais voltada para a transformação social do que para a transmissão cultural." (GADOTTI, 2000, p. 7). É com esse gancho que apresentaremos os quatro desafios, considerados eixos centrais desse artigo, para com base na pedagogia freiriana, tecer reflexões teórico-práticas como forma de resistência aos desafios presentes hoje na educação escolar.

i) Educação emancipatória: Na perspectiva de uma educação emancipadora, a educação escolar deve promover o conhecimento, encarando-o com alegria, criatividade e inovação, em favor dos excluídos (GADOTTI, 2000). A educação emancipatória implica vivências e participação crítica, diálogo comprometido, construções coletivas, conhecimento transformador e ruptura de qualquer tipo de opressão. Para tanto, a educação escolar quando emancipatória é compreendida como "futuridade revolucionária [...] e não pode servir aos interesses do opressor." (FREIRE, 1979, p. 46). Ou seja, de acordo com Paulo Freire, para a educação alcançar o caráter emancipatório, precisa se desvencilhar das amarras tradicionalistas e conservadoras da educação escolar.

Ao criticar o ensino tradicional, no qual a educação é concebida como um ato de depósitos e transferências, Freire (1987) aponta para a necessidade de reiventar a escola, apresentando indicadores de uma escola crítica e libertadora, que possibilite aos sujeitos do ato educativo maior autonomia, visando a superação do ensino meritocrático e competitivo. Nesses termos, o processo emancipatório só acontece mediante uma intencionalidade política voltado para a transformação social, por meio de uma pedagogia da práxis e não de treinamento, dialética e não linear (FRANCO, 2016).

Diante disto, resgatamos as questões formuladas por Gadotti (2000, p. 3), "qual o papel da educação neste novo contexto político? [...] que perspectivas podemos apontar para a educação nesse Terceiro Milênio? Para onde vamos?" Não podemos deixar de considerar que estamos entrando em uma nova década, a qual emerge em um cenário que está cada vez mais voltada para a competitividade e individualidade do que para a solidariedade e coletividade. Encharcada pelos ideais 
individualistas, os quais passaram a ser chamados de empreendedores de si, disfarçadas pelas habilidades e competências, que desembocam na esfera educacional, com vistas a preparar os(as) educandos(as) para atender as demandas do mercado.

Compreendemos que a educação emancipadora deve nascer dentro das escolas, por meio de sua própria inovação e reestruturação curricular, configurando-se como uma ação consciente e participativa, que vai além do ofício dos(as) professores(as), uma vez que há traços culturais, sociais, políticos e econômicos diferentes entre os sujeitos que fazem parte do processo educativo (FRANCO, 2016). Entretanto, o que temos visto é a tendência de desvalorizar as atividades feitas na/pela escola, buscando receitas prontas fora dela, onde pouco ou nada tem de representativo dessa instituição de ensino, tornando os humanos em artefatos tecnicamente construídos. É por essa razão que as contribuições teórico-práticas da pedagogia freiriana são instrumentos de resistência frente a essas "novas" formas de pensar e fazer a educação escolar. Sendo a democracia participativa um dos pilares para pensar o futuro da educação, a qual ao transgredir a ética do mercado contribui para a construção de uma educação crítica e de qualidade social vislumbrando a emancipação humana.

De acordo com as contribuições tecidas por Zitkoski (2004), para emancipar a educação escolar, se faz necessário problematizar o contexto em que estamos inseridos, entretanto, as discussões não devem ser estabelecidas num círculo vicioso por meio de uma crítica fácil, o desafio está em partir da realidade concreta visando a superação dialética dos processos socioculturais desumanizantes. A partir dessas contribuições, destacamos que entre as alternativas para a emancipação da educação em Freire (1987; 1992;1997) evidencia-se que:

- não basta pensarmos em uma emancipação da educação, é preciso organizar um projeto emancipatório de sociedade, denunciado as práticas desumanas e fatalistas;

- é preciso defender a ética humana, a qual é contrária a ética do mercado;

- é necessária uma transgressão ético-política perante a concepção de que a realidade humana é assim mesmo, pronta e acabada;

- se faz necessário uma releitura da sociedade contemporânea a qual é caracterizada pela ideologia fatalista dos modismos;

- é preciso não perder de vista a vocação da natureza humana - vocação para o ser mais, a qual deve ser estimulada nas instituições de ensino;

- a tarefa da educação emancipatória é possibilitar às classes populares o desenvolvimento de sua linguagem a partir de sua realidade concreta.

Por essas indicações, compreendemos que a educação emancipatória se concretiza em um desafio permanente e contemporâneo, especialmente no que diz respeito à (re)construção de uma escola que preconize relações dialógicas, priorizando práticas reflexivas e críticas, problematizando a realidade concreta, construindo um conhecimento coletivo, fortalecendo a interação e o laços afetivos, visando uma formação humana.

ii) Formação humana: O ponto de partida para termos uma sólida formação humana, é, problematizarmos os sentidos e significados do conhecimento oportunizado pela escola. Esse movimento problematizador e preocupado com a transformação do 
contexto educacional está presente na obra Educação como prática da liberdade (FREIRE, 1967). Nela, compreendemos que a democracia, antes de ser uma forma política, é uma forma de vida, que se caracteriza pela transitividade de consciência no comportamento dos homens e mulheres. "Transitividade que não nasce e nem se desenvolve a não ser dentro de certas condições em que o homem seja lançado ao debate, ao exame de seus problemas e dos problemas comuns." (FREIRE, 1967, p. 81). Portanto, para que seja possível realizar uma formação humana no contexto educacional é primordial a participação e mediação democrática da sociedade, bem como, de uma certa disposição mental dos sujeitos por meio de experiências, atitudes e crenças compartilhadaspor todos.

Consequentemente, as problematizações e denúncias de organizações desumanizantes devem ser permanentes, tomando como desafio a construção participativa de uma escola solidificada pela formação humana, almejando a "renovação cultural, esta dialetização que, propriamente falando, não é de ontem, nem de hoje, nem de amanhã, mas uma tarefa permanente de transformação." (FREIRE, 1979, p. 16). A concepção de liberdade, é a matriz que dá sentido à educação podendo ser efetiva "na medida em que os educandos nela tomem parte de maneira livre e crítica." (FREIRE, 1979, p. 27). Nesse sentido, pensar a educação de maneira que viabilize a formação humana implica ultrapassar as fronteiras da escola tradicional, tornando o diálogo uma condição essencial para que o ensinoaprendizagem ocorra.

Outra questão relevante, é sobre a importância dos(as) professores(as) estarem conscientes sobre sua prática, pois de acordo com Freire (1979, p.41), "há inúmeros professores bancários, bemintencionados, que não se dão conta de que servem somente para desumanizar, não percebem que os próprios depósitos contêm contradições sobre a realidade." Um(a) professor(a) com viés humanista deve corresponder seus esforços com o dos(as) alunos(as), comprometendo-se em um pensamento crítico "e numa procura da mútua humanização." (FREIRE, 1979, p.41).

Nesse sentido, Freire $(1979 ; 1987)$ colabora com o desafio da formação humana, principalmente diante da intensificação da globalização que tende a desumanizar o humano, convertendo-o em objeto acrítico. Assim, a educação problematizadora desempenha um importante papel no processo de humanização/libertação/emancipação favorecendo aos sujeitos condições ontológicas para assumirem seu papel transformador no contexto em que vivem. Por isso, um dos caminhos para transformar e humanizar a educação escolar, na perspectiva freiriana, é a conscientização e o diálogo, este último é concebido como fonte do puro amor pelo mundo, pelos homens e mulheres e, quando pautado pela humildade, torna-se palco do encontro com a tarefa comum do aprender e do ensinar. Consequentemente, o diálogo para Freire (1979, p. 43) não existe sem esperança, "se os que dialogam não esperam nada de seus esforços, seu encontro é vazio, estéril, burocrático, cansativo." Portanto, a formação humana para Freire se dá por meio da intencionalidade, amorosidade e, sobretudo, pela esperança no futuro.

Ao tecer essas reflexões, acreditamos na possibilidade de transformação da educação tradicional em uma educação humanizadora. Para Freire (1979), o ultrapassar dessa fronteira (da 
educação bancária para a educação humanizadora) se dá pela instituição de um método ativo de educação, pautado pela crítica, pela reflexão e pela politicidade. Esses elementos aliados à coletividade e à cooperação de todos os sujeitos inseridos no contexto educacional tem potencial de modificar programas educacionais.

Abordar o desafio da formação humana na contemporaneidade, se constitui em uma opção política que ao considerar a não neutralidade do ato educativo se coloca contra os velhos arranjos educacionais que aindaencontram-se enraizados em muitas instituições de ensino. Em consonância a essas contribuições, a formação humana para Freire (1987) deve estar voltada aos princípios da autonomia do ser humano e para o autogoverno, a qual em alguma medida se aproxima dos ideaisa que se espera a formação docente.

iii) Formação docente: "Dentro de uma pedagogia humanizante [...] os professores, líderes revolucionários" (FREIRE, 1979, p. 44), possuem responsabilidade éticas e políticas com os(as) educandos(as), o que thes coloca na condição de se capacitar, antes e durante sua atividade docente, por essa razão que a formação de professores(as) é por nós considerada um desafio permante na educação escolar. Para Freire (1997), a formação permanente presume a condição de inconclusão do(a) professor(a), que é uma condição humana, e ainda, em linha com essas argumentações,

\footnotetext{
a educação é permanente não porque certa linha ideológica ou certa posição política ou certo interesse econômico o exijam. A educação é permanente na razão, de um lado, da finitude do ser humano, de outro, da consciência que ele tem de sua finitude. Mais ainda, pelo fato de, ao longo da história, ter incorporado à sua natureza não apenas saber que vivia, mas saber que sabia e, assim, saber que podia saber mais. A educação e a formação permanente se fundam aí. (FREIRE, 1993a, p. 22-23).
}

A formação permanente das professoras e dos professores busca garantir o princípio da açãoreflexão-ação, ou seja, a formação permanente autêntica, "se funda na experiência de viver a tensão dialética entre teoria e prática. Pensar a prática enquanto a melhor maneira de aperfeiçoar a prática. Pensar a prática através de que se vai reconhecendo a teoria nela embutida." (FREIRE, 1993b, p. 11). Sendo a escola o espaço "coletivo de ensino-aprendizagem, na qual a formação se dirige a todo o grupo de educadores, em oposição às formações em que os professores participam individualmente." (SAUL, SAUL, 2016, p. 26).

Freire (1993b) defende que a formação docente se dê por meio de grupos de formação, envolvendo professoras(es), diretoras(es), coordenadoras(es) pedagógicas(os), merendeiras, vigias, zeladoras(es), pais, mães, alunos e alunas. É preciso também buscar apoio sindical, para que a formação docente seja iluminada pela inteligibilidade política, pelo gosto em saber mais, pela curiosidade epistemológica, fazendo frente de resistência aos "pacotes que sabichões e sabichonas produzem em seus gabinetes numa demonstração inequívoca, [...] de seu autoritarismo.” (FREIRE, 1993b, p. 12).

Nesse sentido, compreendemos que o método apresentado por Shor e Freire (1986), sobre como promover a formação docente está pautado na própria história de aprendizagem e 
reaprendizagem de cada sujeito, ou seja, preponderantemente, a sugestão feita pelos autores é de que se trabalhe e se considere, cada vez mais, a biografia dos(as) professores(as), no sentido de possibilitá-los o compartilhar de suas histórias de aprendizagem. Ou seja, as(os) professoras(es) tem muito a dizer, enfrentam diferentes problemas, "problemas de família, problemas de trabalho, problemas de escola, problemas de transporte, e assim por diante." (SHOR, FREIRE, 1986, p.21). Por isso, nada mais justo que ouví-los(as).

Nesse sentido, superar os desafios da formação docente é trabalhoso e estes não podem ser superados de forma verticalizada por isso a importância de se criar ambientes nos programas de formação oferecidos aos(às) docentes para que estes sujeitos possam falar sobre suas experiências de vida, situando o processo de aprendizagem nas condições concretas de cada grupo. Por essa razão, a primeira via da aprendizagem se dá pela experiência concreta, vivida, numa relação educacional dialética, que é, em si mesma, informal. Esse exercício acrescenta profundidade ao conhecimento, diferenciando-se do currículo tradicional, caracterizando-se pelo viés democrático (SHOR, FREIRE, 1986).

Dentre as obras de Paulo Freire que mais se preocupam com o campo da formação de professores destacamos: Pedagogia do oprimido; Pedagogia da Autonomia: saberes necessários à prática educativa; Professora sim tia não: cartas a quem ousa ensinar e, Medo e ousadia: o cotidiano do professor. Nelas Freire (1987; 1993b; 1997) e Shor e Freire (1986) destacam desafios que precisam ser equacionados, entre eles, citam a concepção bancária da educação; compreensões distorcidas da atividade profissional docente; a sombra ideológica que insiste em pousar nas instituições escolares; a desvalorização salarial; a violência contra as(os) professoras(es), o aumento de doenças ocupacionais e as condições de trabalho precário.

Diante disso, Freire (1997) tece estratégias de enfrentamento perante o desafio da formação docente, entre elas, tem-se a necessidade de fortalecer e democratizar as políticas de formação docente, por meio das quais poderá ser viabilizado ações contra-hegemonicas tanto nas escolas, quanto nas instituições formadoras, impulsionando a luta desses profissionais por condições mais dignas de trabalho e por uma educação gratuita e de qualidade a todos. E ainda, para que essa luta ocorra, as(os) professoras(es) precisam estar motivadas(os) e engajadas(os) com sua formação, mantendo um posicionamento crítico e curioso diante dos problemas que enfrentam cotidianemente (CANÁRIO, 2006; SAUL, SAUL, 2016). Bem como, priorizar a construção do conhecimento em rede, a interatividade entre os pares facilita uma pedagogia autonôma, dialética, dialógica, crítica-reflexiva e democrática. Entretanto, para chegarmos a uma educação emancipatória, que propicie a formação humana e a formação de professores(as) com base no que Freire defende, se faz necessário uma (re)organização curricular da educação escolar.

iv) Organização curricular na escola: Mesmo que Paulo Freire não tenha desenvolvido uma teoria do currículo, traz contribuições para esse campo, por meio das críticas tecidas a educação bancária, indicando a necessidade de ultrapassar a fronteira dos componentes curriculares pré-estabelecidos impostos aos(às) educandos(as). 
Não reduzimos, por isso mesmo, sua compreensão, a do currículo explícito, a uma pura relação de conteúdos pragmáticos. Na verdade, a compreensão do currículo abarca a vida mesma da escola, o que nela se faz ou não se faz, as relações entre todos e todas as que fazem a escola. Abarca a força da ideologia e sua representação não só enquanto ideias, mas como prática concreta. (FREIRE, 1991, p.123).

Portanto, a contribuição do pensamento de Paulo Freire no campo curricular pode ser destacada quando questiona a concepção bancária, indicando as bases para uma educação libertadora e humanizadora. Essa educação nega o ser humano abstrato, ausente no mundo, e o concebe como ser crítico, autônomo e curioso (MENEZES, SANTIAGO, 2014). Permite ao homem e a mulher se constituírem enquanto sujeitos, capazes de transformar o mundo e estabelecer relações com os outros homens e mulheres. Por essa razão, concebemos o diálogo como uma das chaves de leitura presente no pensamento freiriano que pode colaborar na formulação curricular.

Vejamos a partir do próprio Paulo Freire (1979, p. 42),

O diálogo é o encontro entre os homens, mediatizados pelo mundo, para designá-lo. Se, ao dizer suas palavras, ao chamar ao mundo, os homens o transformam, o diálogo impõe-se como o caminho pelo qual os homens encontram seu significado enquanto homens, o diálogo é, pois, uma ne-cessidade existencial.

Sendo o diálogo uma condição exclusivamente humana, é por meio dele, que os seres humanos se solidarizam, se humanizam, refletem e agem no mundo. A prática do diálogo é uma exigência existencial no processo de construção/reconstrução curricular por meio do coletivo, valorizando a participação dos diferentes sujeitos envolvidos na ação educativa, fundamentando a proposta da educação libertadora. Dialogando com a comunidade escolar, ouvindo e refletindo sobre as aspirações do povo é que será possível organizar um currículo na perspectiva emancipatória, não reduzindo a escola como mera transmissora de conteúdos disciplinares.

Pois, para Freire (1991, p. 24),

a reformulação do currículo não pode ser algo feito, elaborado, pensado por uma dúzia de iluminados cujos resultados finais são encaminhados em forma de 'pacotes' para serem executados de acordo ainda com as instruções e guias igualmente elaborados pelos iluminados. A reformulação do currículo é sempre um processo político-pedagógico e, para nós, substantivamente democrático.

O modelo tradicional da educação concebe o conhecimento como algo a ser acatado pelos sujeitos em processo escolar, entretanto, para Freire (1991) precisamos deixar de lado um currículo baseado em acatamentos e construirmos coletivamente um currículo baseado em engajamentos. Entre os problemas localizados quando se trata de um currículo de acatamentos, Young (2011) destaca a interferência dos governos ao alegarem que os problemas econômicos e/ou sociais podem ser solucionados por mudanças nos currículos. Embora Young (2011) reconheça o valor democrático da organização curricular, acatar as exigências políticas dos governos sem pudor, há o perigo de negligenciar o objetivo primordial da educação escolar, que é por meio do currículo escolar, levar os(às) alunos(as) a vivenciar experiências que dificilmente eles teriam acesso em casa. 
É por essa razão que a defesa de Paulo Freire se concentra na reestruturação curricular da/na própria escola, mas para isso, a educação escolar precisa protagonizar projetos por meio de planejamentos de médio e longo prazo com vistas a ser cidadã, inclusiva e democrática, possibilitando a passagem da ingenuidade à crítica (GADOTTI, 2000). Para conseguir o êxito da (re)construção curricular, a tese defendida por Freire (1967) é a construção de círculos de cultura, nos quais são valorizados os diferentes saberes e experiências de todos os sujeitos envolvidos no processo educativo, para que as falas, expressões, desejos e os sonhos das camadas populares sejam representados pelo currículo escolar.

Entre as contribuições de Paulo Freire para o contexto educacional na contemporaneidade destaca-se a importância da construção participativa de um currículo escolar de maneira inter e transdisciplinar, pautado nas dimensões política, ética, cultural, social, pedagógica e estética da realidade local das(os) educandas(os), com vistas a contribuir com a transformação social. A educação como prática da liberdade para Freire (1967) requer um currículo humanizado, integrador, visando a superação da compreensão ingênua e da mera instrumentalização dos(as) educandos(as). Nesse sentido, a organização curricular da escola na perspectiva freiriana, jamais pode, em nome da disciplina, castrar a criatividade dos(as) educandos(as), tão pouco, pode o(a) educador(a) ensinar a leitura e a escrita aos(às) seus/suas alunos e alunas dando as costas à leitura de mundo desses sujeitos (FREIRE, 1992).

\section{CONSIDERAÇÕES FINAIS}

Pensar os desafios contemporâneos da educação escolar na esteira da pedagogia freiriana, requer a valorização do ser humano concreto e integral, que necessita humanizar-se uns com os outros, ensinando e aprendendo sob a perspectiva da educação popular libertadora/emancipatória. Por isso, a educação na contemporaneidade implica em vivências, posicionamento crítico, diálogo, comprometimento, construções coletivas e conhecimento transformador. Trazer para o debate os desafios atuais da educação escolar: educação emancipatória, formação humana, formação de professores e organização curricular na escolar, requer um olhar atento ao contexto atual, no qual a sociedade e, consequentemente, a escola encontra-se inserida. Portanto, para compreendê-los é preciso considerar a totalidade das relações educacionais, as quais não são neutras, encontram-se encharcadas na/pela realidade concreta, estando diretamente vinculadas a realidade social, política e econômica da sociedade.

Em face das análises realizadas, consideramos a importância da educação escolar conhecer a realidade concreta dos sujeitos, perspectivando intervenções a fim de restaurar a humanidade roubada pelos aparelhos hegemônicos, que oprimem, exploram e violentam os sujeitos (oprimidos e opressores) em razão do poder e da força que intencionam o ter em detrimento do ser mais. Nesse sentido, as obras de Freire, nos apresentam alguns princípios de resistência perante os desafios educacionais contemporâneos: o diálogo como via de uma educação emancipadora e humanizadora, e a própria educação escolar objetivando a conscientização de homens e mulheres, por meio de práticas pedagógicas que exercitem a cooperação e a comunhão entre os sujeitos. Concebemos as 
concepções freirianas de educação popular libertadora e de práxis político-educativa como concepções que permanencem potentes para os desafios emergentes, presente o contexto educativo atual.

É válido ressaltar que não pretendemos, com o presente texto, esgotar as contribuições freirianas para a educação escolar, apenas apontar, a partir de algumas de suas obras, contribuições diante dos desafios contemporâneos para a construção de uma educação mais justa e democrática. Consideramos, ainda, que diante das reflexões aqui tecidas, encontram-se subsídios importantes para pesquisas futuras, principalmente no que diz respeito a estratégias de reformulação/restruturação da educação escolar, a fim de contemplá-la com seriedade, curiosidade, consciência crítica, visando a diminuição do risco de alienação, castração e domesticação dos sujeitos. Lembramo-nos que o sonho de Freire (1992) era de uma pedagogia da esperança, de uma educação democrática conscientizadora, que estimule os sujeitos, homens e mulheres, ao gosto da pergunta, despertando neles(as) a paixão pelo saber, pela curiosidade, pela liberdade de criação, aventura e risco. O diálogo, sob o horizonte do conceito de práxis político-educativa, é um caminho vigoroso para o projeto de educação emancipador e humanizador, a qual pressupõe pedagogias críticas, problematizadoras, criativas e esperançosas.

\section{REFERÊNCIAS}

1. CANÁRIO, Rui. A escola tem futuro? Das promessas às incertezas. Porto Alegre: Artmed, 2006.

2. DEMO, Pedro; SILVA, Renan Antônio. Atividades de aprendizagem na escola. Revista Humanidades e Inovação, Palmas, v.8, n. 5, p. 422-435, 2000. ISSN: 2358-8322. Disponível em: $<$ https://revista.unitins.br/index.php/humanidadeseinovacao/article/view/2872>. Acesso em: 10 ago. 2020.

3. DOWBOR, Ladislau. À sombra desta mangueira [Prefácio]. In.: FREIRE, Paulo. À sombra desta mangueira, São Paulo: Editora Olho d’Água, 1995.

4. FRANCO, Maria Amélia do Rosario Santoro. Prática pedagógica e docência: um olhar a partir da epistemologia do conceito. Revista Brasileira de Estudos Pedagógicos, Brasília, v. 97, n. 247, p. 534-551, dez. 2016.2 Disponível em: $<$ http://www.scielo.br/scielo.php?script=sci_arttext\&pid=S2176$66812016000300534 \&$ Ing=pt\&nrm=iso>. Acesso em 01 set. 2020.

5. FREIRE, Paulo. Educação como Prática da Liberdade. Rio de Janeiro: Editora Paz e Terra, 1967.

6. FREIRE, Paulo. Conscientização: teoria e prática da libertação: uma introdução ao pensamento de Paulo Freire. São Paulo: Corte \& Moraes, 1979. 
7. FREIRE, Paulo. Ação cultural para a liberdade e outros escritos. $5^{\text {a }}$ ed., Rio de Janeiro: Paz e Terra, 1981.

8. FREIRE, Paulo. Pedagogia do oprimido, 17ª ed. Rio de Janeiro, Paz e Terra, 1987.

9. FREIRE, Paulo. A educação na cidade. São Paulo: Cortez Editora, 1991.

10. FREIRE, Paulo. Pedagogia da esperança: um reencontro com a pedagogia do oprimido. Rio de Janeiro: Paz e Terra, 1992.

11. FREIRE, Paulo. Política e educação. Indaiatuba: Villa das Letras Editora, 1993a.

12. FREIRE, Paulo. Professora sim tia não: cartas a quem ousa ensinar. São Paulo: Paz e Terra, 1993b.

13. FREIRE, Paulo. À sombra desta mangueira. São Paulo: Editora Olho d'Água, 1995.

14. FREIRE, Paulo. A pedagogia da autonomia: saberes necessários à prática educativa. São Paulo: Paz e Terra, 1997.

15. GADOTTI, MOACIR. Perspectivas atuais da educação. São Paulo em Perspectiva, São Paulo, v. 14, n. 2, p. 03-11, jun. 2000. Disponível em: /scielo.php?script=sci_arttext\&pid=S010288392000000200002\&lng=en\&nrm=iso>. Acesso em: 09 ago. 2020. DOI: http://dx.doi.org/10.1590/S0102-88392000000200002.

16. IVENICKI, Ana. A Escola e seus Desafios na Contemporaneidade. Ensaio: Avaliação e Políticas Públicas em Educação, Rio de Janeiro, v. 27, n. 102, p. 1-8, mar. 2019. Disponível em: $<$ http://www.scielo.br/scielo.php?script=sci_arttext\&pid=S0104-

40362019000100001\&Ing=en\&nrm=iso>. Acesso em: 09 ago. 2020. DOI: https://doi.org/10.1590/s0104-40362018002700001.

17. MENEZES, Marilia Gabriela de; SANTIAGO, Maria Eliete. Contribuição do pensamento de Paulo Freire para o paradigma curricular crítico-emancipatório. Pro-Posições, Campinas, v. 25, n. 3, p. 45-62, dez. 2014. Disponível em: <http://www.scielo.br/scielo.php?script=sci_arttext\&pid=S0103$73072014000300003 \&$ Ing=en\&nrm=iso>. Acesso em: 17 set. 2020.

18. SHOR, Ira; FREIRE, Paulo. Medo e Ousadia: o Cotidiano do Professor. Rio de Janeiro: Paz e Terra, 1986. 
19. TEIXEIRA, Anísio. Estado atual da educação. Revista Brasileira de Estudos Pedagógicos. Rio de Janeiro, v.39, n.89, p.8-16, jan./mar. 1963. ISSN 0034-7183. Disponível em: <http://portal.inep.gov.br/documents/186968/489316/Revista+Brasileira+de+Estudos+Pedag\%C3\% B3gicos+\%28RBEP\%29+-+Num+212/cbeadc35-ec0d-4b12-9f05-c09eb52c7a2d?version=1.3>. Acesso em: 10 ago. 2020.

20. TRIVIÑOS, Augusto Nibaldo Silva. Introdução à pesquisa em ciências sociais: a pesquisa qualitativa em educação. São Paulo: Atlas, 1987.

21. SAUL, Ana Maria; SAUL, Alexandre. Contribuições de Paulo Freire para a formação de educadores: fundamentos e práticas de um paradigma contra-hegemônico. Educar em Revista, Curitiba, n. 61, p. 19-35, jul./set. 2016. Disponível em: <https://www.scielo.br/scielo.php?script=sci_arttext\&pid=S010440602016000300019\&Ing=en\&nrm=iso>. Acesso em: 10 ago. 2020. DOI: http://dx.doi.org/10.1590/0104-4060.46865.

22. YOUNG, Michael. O futuro da educação em uma sociedade do conhecimento: o argumento radical em defesa de um currículo centrado em disciplinas. Revista Brasileira de Educação, Rio de Janeiro, v. 16 n. 48, p. 609-810, set./dez. 2011. Disponível em: <https://www.scielo.br/pdf/rbedu/v16n48/v16n48a05.pdf>. Acesso em: 10 ago. 2020.

23. ZITKOSKI, Jaime José. Educação populare emancipação social: Convergências na proposta de Freire e Habermas.In: 26ª REUNIÃO ANUAL da ANPED, 2004, Caxambú. Anais [...] Caxambú, 2004.

\section{Mônica Tessaro}

Doutoranda em Educação pela Universidade do Oeste de Santa Catarina (UNOESC), Mestra em Educação pela Universidade Comunitária da Região de Chapecó (UNOCHAPECO), graduada em Psicologia pela Unochapeco. Bolsista Capes, cod. de financiamento 001.

\section{Fernanda dos Santos Paulo}

Doutora em Educação Pela UNISINOS, Mestra em Educação pela Universidade Federal do Rio Grande do Sul/UFRGS, Especialista em Educação Popular: Gestão de Movimentos Sociais pelo Brava Gente e Instituto IVOTI. Graduada em Pedagogia pelo Centro Universitário Metodista/IPA. Professora do Programa de Pós-Graduanção em Educação (PPGEd) da UNOESC.

\section{Maria Teresa Ceron Trevisol}


Doutora em Psicologia Escolar e do Desenvolvimento Humano pela Universidade de São Paulo (USP). Mestra em Educação pela Pontifícia Universidade Católica do Rio Grande do Sul. Pedagoga pela Universidade do Oeste de Santa Catarina. Professora do Programa de Pós-Graduanção em Educação (PPGEd) da UNOESC.

\section{Como citar este documento:}

TESSARO, Mônica; PAULO, Fernanda dos Santos; TREVISOL, Maria Teresa Ceron. CONCEPÇÕES FREIRIANAS PARA A EDUCAÇÃO NA CONTEMPORANEIDADE: DESAFIOS EMERGENTES. Reflexão e Ação, Santa Cruz do Sul, v. 29, n. 1, p. 202-217, jan. 2021. ISSN 1982-9949. Acesso em: doi: http://dx.doi.org/10.17058/rea.v29i1.14743. 